\title{
Bem-vindo a Bordo da Acta Médica Portuguesa, Bem-vindos à Primeira Divisão Internacional!
}

\author{
Welcome Aboard the Acta Medica Portuguesa, Welcome to the First \\ International Division!
}

Rui Tato MARINHO ${ }^{1,2}$, Helena DONATO ${ }^{3,4}$

Acta Med Port 2014 Sep-Oct;27(5):533-534

Palavras-chave: Revistas; Publicação; Portugal.

Keywords: Periodicals as Topic; Publishing; Portugal.

A Acta Médica Portuguesa entrou no quarto ano da nova fase. Cumprem-se agora 35 anos de existência e de indexação na PubMed / Medline. Um dos objectivos principais foi atingido em 2010 que se traduziu na atribuição de Factor de Impacto pelo Journal Citation Reports após a indexação na Web of Science da Thomson Reuters. Em Portugal apenas quatro revistas médicas têm de momento estas duas atribuições que espelham um determinado patamar de qualidade e internacionalização. São elas a Revista Portuguesa de Pneumologia, a Revista Portuguesa de Cardiologia e a Acta Reumatológica Portuguesa. Os autores destas 'Big Four' são responsáveis por mais de 7600 artigos na Medline, a grande base de referências de artigos biomédicos a nível mundial. $E$ a tendência em todas é que o Factor de Impacto suba nos próximos anos. Citem-nos, estudem-nos, divulguem-nos s.f.f. (se faz favor!). São 35 anos da história da publicação científica portuguesa. A maioria dos médicos no activo em Portugal é o produto da formação do $12^{\circ}$ melhor Serviço Nacional de Saúde do Mundo, de acordo com os parâmetros da Organização Mundial de Saúde no ano 2000. ${ }^{1}$

A Acta Médica Portuguesa recebe quase 750 artigos por ano. A taxa de rejeição é muito muito elevada, de $83 \%$. Estamos na primeira divisão internacional, a par do New England Journal of Medicine, do Lancet, Annals of Internal Medicine, British Medical Journal, entre outras. A nossa posição é no lugar 132 entre 150 revistas na categoria 'Medicine, General and Internal'.

É necessário o reforço e profissionalização da estrutura de suporte e apoio pela parte da própria Ordem dos Médicos, a proprietária da Acta Médica Portuguesa: a Acta Médica Portuguesa deverá estar integrada de forma sustentável e bem marcada no organigrama da Ordem dos Médicos, para que se mantenha viva e activa para lá da mudança da sua equipa. O núcleo duro de uma revista como a Acta Médica Portuguesa tem uma actividade complexa e engloba $10-15$ profissionais dos mais variados sectores (coorde- nador, assistente editorial, designer, tradutor, informático, assessor técnico, editores-associados, etc., etc.). Tem que ter autonomia científica e de gestão no seio de uma estrutura como a nossa Ordem dos Médicos.

O cargo de Editor-Chefe tem que ser semiprofissionalizado (concurso, contrato, compensação monetária ou em bolsa de horas, etc.) dada a exigência e as implicações para a vida pessoal, profissional e até familiar. Não andaremos muito longe da realidade se afirmarmos que o tempo alocado ao conjunto de actividades no âmbito de um qualquer editor-chefe desta revista será de um dia por semana.

Apesar da relevância da língua portuguesa, falada e escrita nos ditos quatro ou mais cantos do Mundo, a língua mãe do artigo científico é de forma indubitável o inglês. ${ }^{2},{ }^{3} \mathrm{O}$ grosso do dito 'mercado das citações' está de modo muito marcado na América do Norte e na Europa Ocidental. ${ }^{4}$ Os países dos outros continentes terão que publicar em inglês, se querem atingir o alcance e a divulgação máxima. ${ }^{5}$ $\mathrm{O}$ artigo mais recente com mais citações da Acta Médica foi publicado em inglês. ${ }^{6}$

O nosso consumidor final será sempre o autor e o artigo que é publicado na nossa revista. Queremos promovê-lo, divulgá-lo, aos quatro cantos. Queremos dar a possibilidade de ter citações na maior quantidade possível. O artigo é o nosso 'menino de oiro'. Queremos fazer tudo o que estiver ao nosso alcance pelos nossos autores e pelos nossos artigos.

Vamos organizar dentro em breve o III Simpósio da Acta Médica Portuguesa, que terá lugar na sede da Ordem dos Médicos em Lisboa no dia 22 de Novembro. Estarão presentes 15 oradores, seis revistas científicas portuguesas e uma editora internacional (Springer Science). Queremos promover o 'How to Do' na área do medical editing e do medical publishing. ${ }^{7}$

Publish or perish. Our vision is to create 'a healthier world'. ...In order to help our patients. To help doctors to make better decisions.

1. Editor-Chefe. Acta Médica Portuguesa. Lisboa. Portugal.

2. Serviço de Gastrenterologia e Hepatologia. Hospital de Santa Maria. Centro Hospitalar Lisboa Norte. Portugal.

3. Editora Associada. Acta Médica Portuguesa. Lisboa. Portugal.

4. Serviço de Documentação. Centro Hospitalar e Universitário de Coimbra. Coimbra. Portugal.

Recebido: 23 de Outubro de 2014 - Aceite: 23 de Outubro de 2014 | Copyright ( $)$ Ordem dos Médicos 2014 


\section{REFERÊNCIAS}

1. Tandon A, Murray CJ, Lauer J, Evans D. Measuring overall health system performance for 191 countries. GPE Discussion Paper Series: No. 30. EIP/GPE/EQC World Health Organization 2000.[consultado 2014 Out 20] Disponivel em: http://www.who.int/healthinfo/paper30.pdf.

2. Vinther S, Rosenberg J. Impact factor trends for general medical journals: non-English-language journals are lacking behind. Swiss Med Wkly. 2012;142:w13572.

3. Gómez FG. La importancia para nuestra revista de publicar en inglés. Acta Ortop Mex. 2010;24:289-90.

4. Drubin DG, Kellogg DR. English as the universal language of science: opportunities and challenges. Mol Biol Cell. 2012;23:1399.

5. Lira RP, Vieira RM, Gonçalves FA, Ferreira MC, Maziero D, Passos $\mathrm{TH}$, et al. Influence of English language in the number of citations of articles published in Brazilian journals of ophthalmology. Arq Bras Oftalmol. 2013;76:26-8.

6. Amaral L. Thioridazine: an old neuroleptic effective against totally drug resistant tuberculosis. Acta Med Port. 2012 Mar-Apr;25:118-21.

7. Marinho RT, Donato H, Fernandez-Llimos F, Massano J, Silva JM, Almeida $\mathrm{M}$, et al. Think tank: relatório estratégico sobre publicação científica biomédica em Portugal. Acta Med Port. 2014;27:1-3.

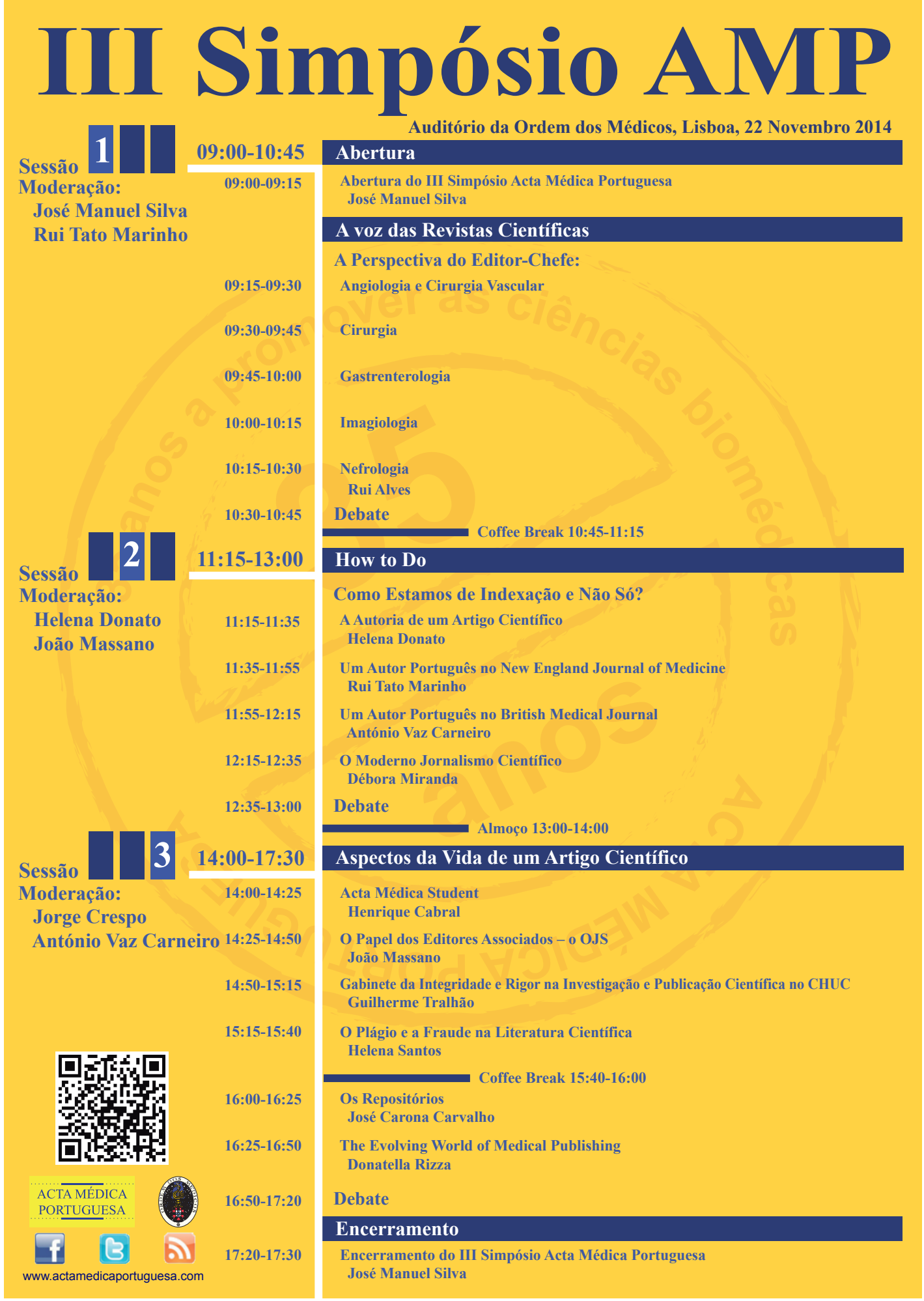




\section{Bem-vindo a Bordo da Acta Médica Portuguesa, Bem-vindos à Primeira Divisão Internacional!}

Acta Med Port 2014:27:533-534

Publicado pela Acta Médica Portuguesa, a Revista Científica da Ordem dos Médicos

Av. Almirante Gago Coutinho, 151

1749-084 Lisboa, Portugal.

Tel: +351218428215

E-mail: submissao@actamedicaportuguesa.com

www.actamedicaportuguesa.com

ISSN:0870-399X | e-ISSN: 1646-0758

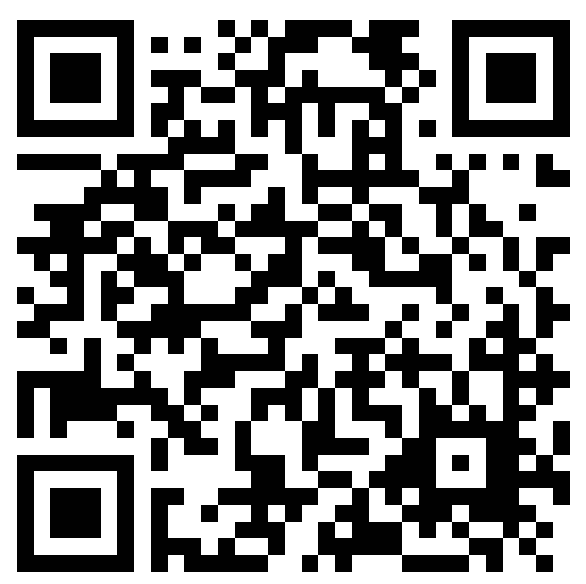

